\title{
Vulnerabilidade Urbana: um resgate da visão transescalar
}

\author{
Urban Vulnerability: a rescue of the vision transcales
}

Vulnerabilidad Urbana: un rescate a la visión transescalar

\author{
Priscila Maria de Freitas ${ }^{1}$ \\ https://orcid.org/0000-0001-8420-2467 \\ Mário Valério Filho² \\ https://orcid.org/0000-0001-9268-8970 \\ Rodolfo Moreda Mendes ${ }^{3}$ \\ https://orcid.org/0000-0003-1833-3084
}

RESUMO: Este início do século XXI já traz diversos exemplos de desastres ocorridos em virtude da atual relação do homem com o meio ambiente. E, em conjunto aos estudos dos perigos e risco, necessários para enfrentamento de tais desastres, cresce a conceituação de vulnerabilidade como fragilidade neste contexto; contudo nas áreas das ciências sociais a vulnerabilidade é entendida em conjunto com as desigualdades sociais estruturadas historicamente. Assim, este artigo busca levar luz à relevância e abrangência do conceito de vulnerabilidade e valorizar o debate já realizado sobre essa temática por autores do Sul. Analisando por meio de revisão bibliográfica, apresenta-se uma proposta de matriz do pensamento da vulnerabilidade urbana, entendida como a expressão máxima do ônus do processo de urbanização, como um resgate a visão transescalar da vulnerabilidade urbana, demonstrando que se faz necessário mais trabalhos sobre essa temática, tal como o aprofundando de estudos já existentes e abordando o conceito de vulnerabilidade urbana, compreendendo e contemplando o processo histórico na análise; entendendo que as mazelas sociais não possuem apenas o olhar de causa e efeito, mas sim de sobreposição dos processos dados num determinado espaço e tempo.

PALAVRAS-CHAVES: Vulnerabilidade urbana. Planejamento urbano. Epistemologias do sul.

\footnotetext{
${ }^{1}$ Doutoranda em Planejamento Urbano e Regional pela Universidade do Vale do Paraíba. Arquiteta e urbanista da Prefeitura Municipal de Jacareí. E-mail: arqpriscilafreitas@yahoo.com.br.

${ }^{2}$ Doutor em Agronomia pela Escola Superior de Agricultura Luiz de Queiroz-USP. Professor da Universidade do Vale do Paraíba. E-mail: mvalerio@univap.br.

3 Doutor em Engenharia Geotécnica pela Escola Politécnica da Universidade de São Paulo. Professor da Universidade do Vale do Paraíba. E-mail: rmm.cemaden@gmail.com.
} 


\begin{abstract}
This beginning of the 21st century already brings several examples of disasters that occurred due to the current relationship between man and the environment. Along with the studies of dangers and risk, which are necessary to face such disasters, the concept of vulnerability grows as fragility in this context; however, in the area of social sciences, vulnerability is understood in conjunction with historically structured social inequalities. Thus, this article intent to elucidate the relevance and scope of the concept of vulnerability and to value the debate already carried out on this subject by authors from the South. Based on a bibliographic review, a proposal for a matrix of thought about urban vulnerability is presented, understood as the maximum expression of engagement in the urbanization process, as a rescue of the scalable view of urban vulnerability. Demonstrating that more work is needed on this theme, as well as deepening existing studies and addressing the concept of urban vulnerability, understanding and contemplating the historical process in the analysis; understand that social problems are not just a question of cause and effect, but of overlapping processes in a given space and time.
\end{abstract}

KEYWORDS: Urban vulnerability. Urban planning. Epistemologies of the south.

RESUMEN: Este inicio del siglo XXI ya trae varios ejemplos de desastres que se han producido debido a la relación actual entre el hombre y el medio ambiente. $Y$, junto con los estudios de peligros y riesgos, necesario para enfrentar tales desastres, el concepto de vulnerabilidad crece como fragilidad en este contexto; sin embargo, en las áreas de las ciencias sociales, la vulnerabilidad se entiende en conjunto con las desigualdades sociales históricamente estructuradas. Así, este artículo busca esclarecer la pertinencia y alcances del concepto de vulnerabilidad y poner en valor el debate ya sostenido sobre este tema por autores del Sur. Analizando a través de una revisión bibliográfica, se presenta una propuesta de matriz de pensamiento sobre vulnerabilidad urbana, entendida como la máxima expresión del peso del proceso de urbanización, como rescate de la visión escalable de la vulnerabilidad urbana. Demostrando que se necesita más trabajo en este tema, así como profundizar los estudios existentes y abordar el concepto de vulnerabilidad urbana, entendiendo y contemplando el proceso histórico en el análisis; entendiendo que los problemas sociales no solo tienen una mirada de causa y efecto, sino de procesos superpuestos dados en un espacio y tiempo determinados

PALABRAS CLAVES: Vulnerabilidad urbana. Planificación urbana. Epistemologías del sur.

\title{
INTRODUÇÃO
}

A atual relação do homem com o meio ambiente não tem sido de uma convivência harmoniosa, mas sim de confrontos; o homem explora o meio ambiente para usá-lo como recurso sem respeitar os ciclos naturais. O resultado deste confronto tem se dado nos desastres, como por exemplo estes das últimas duas décadas: rompimento da barragem de Brumadinho, estado de Minas Gerais/Brasil, em janeiro/2019; rompimento da barragem de Mariana, Minas Gerais/Brasil, em novembro/2015; vazamento de petróleo no Golfo do México, em abril/2010; tsunami no Oceano Indico, que atingiu principalmente a Indonésia, em dezembro/2004; vazamento de óleo na Baía de Guanabara, em janeiro/2000 no Rio de Janeiro/Brasil.

Os perigos são monitorados pelos órgãos estatais para que não sejam causados danos, ou, se causarem, que seja o menor possível. Neste contexto se encontra a estrutura do pensamento da vulnerabilidade frente aos estudos de riscos e perigos, contudo nas 
áreas das ciências sociais a vulnerabilidade percorre outro caminho. Assim, partindo da hipótese de que a construção de um pensamento direciona a estrutura da ação subsequente, de tal modo intenta-se compreender a vulnerabilidade urbana (ou a vulnerabilidade do urbano) no contexto das ciências sociais, qual seja, compreendendo a vulnerabilidade em conjunto com as desigualdades sociais estruturadas historicamente.

Este trabalho é parte integrante da pesquisa da tese de doutorado em Planejamento Urbano e Regional, realizado no Instituto de Pesquisa e Desenvolvimento da Universidade do Vale do Paraíba - IP\&D/UNIVAP, cuja motivação foi dada pela percepção dos problemas urbanos contemporâneos derivados do modo de produção espacial, que criam e consolidam as desigualdades socioespaciais ignorando o debate ambiental. Dentre os problemas urbanos, destaca-se a existência de áreas em condições de vulnerabilidade localizadas dentro do contexto urbano, e que possuem simultaneamente condições de exclusão social, degradação ambiental e segregação espacial.

Desta forma, a partir de leituras bibliográficas, apresenta-se uma proposta de matriz do pensamento da vulnerabilidade urbana, entendida como a expressão máxima do ônus do processo de urbanização, como um resgate da visão transescalar da vulnerabilidade urbana, a fim de, sem ignorar as ações dos agentes e atores no processo de gestão do território, proporcionar subsídios para uma proposta efetiva tecnicamente de política pública nestes territórios. Se apoiando no conceito das epistemologias do Sul de Boaventura de Sousa Santos (NUNES, 2013; SANTOS, 2013a, 2013b), este artigo tem por objetivo levar luz à relevância e abrangência do conceito de vulnerabilidade; e de valorizar o debate já realizado sobre essa temática por autores do Sul.

\section{QUESTÃO AMBIENTAL COMO QUESTÃO DE ESTADO?}

A partir das décadas de 1950 e 1960, na Pós II Grande Guerra Mundial, o modelo de vida valorizado, e que se expandiu globalmente até os dias atuais, foi o consumismo. Esta realidade social de alguns países e adotada como modelo a ser seguido acelerou os desastres globais oriundos dos limites ambientais. Como contraponto a estes acontecimentos nesta nova escala, na década de 1970 ocorre a conferência de Estocolmo na Suécia, consolidando o relevante debate que vinha se formando sobre a questão ambiental, visando a compreensão das dinâmicas naturais, seus limites e enfrentamentos possíveis. A partir de então, o reconhecimento e aceite da questão ambiental se deu em todas as escalas e esferas de governo, como se pode notar pelo posicionamento dos órgãos internacionais ligados aos processos de gestão dos territórios nacionais num mundo economicamente globalizado, quais sejam, da ONU (Organização das Nações Unidas), 
suas conferências de desenvolvimento sustentável - Eco 92, RIO+10 e RIO+20 - e posterior Objetivos de Desenvolvimento Sustentável - ODSs (ONU, 2020)

Estes eventos de abrangência internacional abriram o debate de diversos temas ambientais como a "pegada ecológica" (DIAS, 2015) e as mudanças climáticas (NOBRE, 2001), e promoveram uma maciça divulgação da sustentabilidade (FREITAS, 2015). Tais discursos, por um lado, validam a agenda e o debate ambiental, ao mesmo tempo em que direcionam um olhar específico voltado a promover indicadores, metodologias de diagnóstico e intervenções que minimizem os impactos ambientais de forma a manter e não questionar o sistema econômico vigente.

Neste aspecto, propõe-se refletir a questão ambiental sob a ótica da epistemologia do Sul, qual seja, que cada conceito possui uma história que o estrutura e acaba por direcionar e regulamentar a construção das ações subsequentes. Para tanto se recorre a Santos, Araújo e Baumgarten (2016) com o entendimento das epistemologias do Sul, que parte do princípio de que a compreensão do mundo excede em muito ao pensamento europeu, considerado hegemônico e que gera invisibilidades.

A produção de invisibilidades é assegurada pelas cinco monoculturas do pensamento moderno: a monocultura do saber e do rigor do saber cria o ignorante, a monocultura do tempo linear determina o residual, a monocultura da naturalização das diferenças legitima a classificação do inferior, a monocultura do universalismo abstrato demarca o que é local e estabelece a sua irrelevância e a monocultura dos critérios de produtividade capitalista decreta o improdutivo (SANTOS; ARAÚJO; BAUMGARTEN, 2016, p. 16).

Em contraponto às monoculturas o autor propõe ecologias, ou seja, processos que aceitem as diferenças, que reconheçam as dinâmicas locais, que abriguem sistemas alternativos em seus diversos tempos e por meio de saberes múltiplos. Buscando explorar a pluralidade por meio de uma relação não hierárquica entre os saberes e seres humanos, as epistemologias do Sul tratam de uma proposta de reconhecer que há mais de uma narrativa nos lugares, em especial nos países explorados e considerados em desenvolvimento, como o caso do Brasil, onde a narrativa hegemônica se coloca como superior e, portanto, a versão válida.

Desta forma, as epistemologias do Sul têm por "[...] ideia-chave de que não há justiça global sem justiça cognitiva global" (SANTOS; ARAÚJO; BAUMGARTEN, 2016, p. 18), assim para que os seres humanos se reconheçam e dialoguem como iguais, as suas narrativas devem ser reconhecidas no mesmo patamar; qual seja, a não hierarquização das falas se torna um caminho para a não dominação entre sujeitos.

Ao tratar de epistemologias é interessante pontuar que Santos, Araújo e Baumgarten tecem uma relação antagônica entre monoculturas e ecologias, considerando monocultura a 
hierarquização com a diminuição e até anulação do dominado, enquanto ecologias considera a convivência não hierárquica entre diferentes. Tal relação antagônica também pode ser percebida nos escritos de José Eli da Veiga (1993) ao relatar como a ciência econômica moderna se relacionava com a natureza, "[...] a tendência largamente dominante na ciência econômica contemporânea é a de considerar a propriedade dos recursos naturais como simples bem de capital, e sua renda como lucro" (VEIGA, 1993, p. 160).

Sendo a natureza e seus sistemas considerados apenas como recursos não havia debate a ser realizado, apenas bem de capital a ser explorado; há uma distinção (e disputa) de entendimento e de ações geradas pelos termos meio ambiente e recursos naturais. Esta realidade observada nas teorias econômicas que direcionam a atuação do homem em sociedade e, por consequência, sua forma de ocupação sobre o território, já foi observada em 1945, ao se chamar a atenção para a depredação ambiental que vem acompanhando cada ciclo econômico brasileiro (PRADO Jr., 1945), mostrando que as dinâmicas econômicas e os modos de produção de bens e serviços trataram, por séculos, o meio ambiente apenas como recurso.

O mesmo pode ser observado no final do século XX que foi marcado pelas mudanças climáticas e pela visibilidade dos limites e finitude do meio ambiente, quais sejam, por mudanças abruptas de temperatura, pela poluição dos mares e do ar, a constatação do buraco na camada de ozônio e diversos eventos climáticos nas áreas urbanas, demonstrando que as práticas exploratórias em escala industrial trazem consequências negativas para o meio ambiente e, por decorrência, para as áreas de ocupação urbana e para a saúde da população.

Sem questionar o sistema econômico hegemônico, nem o seu modo de produção e consumo, foi proposta uma nova agenda de debates entre governos sobre formas de exploração da natureza e os impactos ocasionados à vida humana. Tais debates haviam se iniciado no meio técnico científico, como pode ser visto na proposta do ecodesenvolvimento de Ignacy Sachs (1986), e se estenderam para o meio político econômico notado na Conferência das Nações Unidas para o Meio Ambiente Humano, em Estocolmo na Suécia, de 1972, e a agenda sobre o desenvolvimento sustentável.

É interessante notar que "[...] em curto espaço de tempo, o aquecimento global saltou de um tema entre muitos outros no rosário ambientalista para a condição de maior desafio do século 21. A questão já estava presente na Cúpula da Terra em 1992" (HOGAN, 2009, p. 11), evento sediado no Rio de Janeiro e com a representação de mais de cem países, lá foi firmada a Agenda 21 Global, ou seja, um documento que atribuía responsabilidade aos Estados referente à preservação do meio ambiente ou à diminuição na exploração dos recursos naturais, visando a diminuir o impacto, ou degradação do meio ambiente. 
Concomitante com a brevidade da questão ambiental na sociedade, as dinâmicas relatadas demonstram que o Estado foi colocado como salvaguarda do meio ambiente. $O$ Estado é um agente social num determinado espaço, na medida em que tem o papel de regulador das atividades dos demais agentes que atuam no território; a definição de Estado pode ser dada por um conjunto de pensadores, como Platão, Espinoza, Marx e Weber (STEINBERGER, 2013). Assim o Estado é fruto do contexto social no qual está inserido, sendo responsável por zelar pelos espaços públicos, pelos habitantes e pelo meio ambiente.

O Estado, além de possuir uma relação direta com o modelo econômico vigente, também é responsável por influenciar no processo de urbanização, qual seja, a produção do espaço, modos de produção de benfeitorias e direcionamento da forma de vida são papeis realizados pelo Estado por meio dos arranjos institucionais. Atualmente, estas relações passam pelo momento neoliberalista, que valorizou um forte agente que também atua no território e demanda a diminuição da ação do Estado, o mercado.

Sob a lógica do livre mercado, há a solicitação pelos agentes hegemônicos capitalistas da diminuição do alcance do Estado. Contudo como o sistema capitalista vivencia crises frequentes, nestas o Estado é convocado a restaurar a ordem, ou melhor, a estrutura mínima necessária para a manutenção das atividades mercadológicas. Sob este contexto o Estado atual tem a perspectiva de ações por meio de políticas públicas, que podem gerar ora a manutenção e (re)produção das condições do sistema neoliberal, ora a estruturação, dentro da democracia representativa e participativa, de políticas redistributivas.

Também sob esta conjuntura se encontra o debate da elaboração (ou não) de um projeto de nação. Tal projeto é uma proposta de identidade nacional, e também se faz como uma proposta de Estado; já que, a partir deste projeto de nação, são traçadas as futuras decisões e planejamentos de médio e longo prazo a serem realizados pelo Estado. "O mundo se torna fluido, graças à informação, mas também ao dinheiro. Além disso, o território deixa de ter fronteiras rígidas, o que leva ao enfraquecimento e à mudança de natureza dos Estados nacionais" (SANTOS, 2002, p. 32).

A globalização neoliberal não impede, mas dificulta a criação ou manutenção de um projeto nacional; uma vez que esta modernidade líquida busca o caminhar fluído do livre mercado e o Estado Nacional visa uma identidade nacional, a valorização cultural e (esperase), um estado democrático com política redistributiva.

Como vê-se, as composições dadas no Estado e, consequentemente, nos arranjos institucionais, são locais de disputa, já que ali são articuladas as decisões e direcionamentos dos modos de apropriação do território e das estruturas econômicas produtivas. Tais processos de governança passam inicialmente pela disputa dos locais nos quais se dão os 
arranjos institucionais, como os conselhos ou agências reguladoras. Desta forma, é a este Estado que foi delegado o dever de salvaguardar o meio ambiente.

\section{ESPAÇO, RISCO E VULNERABILIDADE}

Gottdiener (1993, p. 201) conceitua o espaço como produto social e uma das instâncias da sociedade, entendendo que "[...] o ambiente construído deve ser encarado como se estivesse embutido dentro de uma matriz complexa de organização socioeconômica, envolvendo uma estrutura burocrática de comparação para a acumulação de capital numa escala mundial”. Para Lefebvre (2006) o conceito de espaço está ligado à produção social, possuindo dois aspectos que coexistem. Ora o espaço pode ser meio, ou seja, local de produção, acumulação econômica, com o seu valor de troca; e ora produto, ou seja, um reflexo das relações sociais, tendo o seu valor de uso. Estes dois autores auxiliam a compreender que o espaço urbano vai para além dos aspectos físicos com as infraestruturas urbanas, englobando no seu debate os aspectos naturais, econômicos, institucionais e sociais.

As características de um município, como por exemplo, a priorização de investimento em instalação de infraestrutura urbana numa determinada área, em detrimento das demais, é resultado do processo de disputa entre espaços (e agentes sociais) deste território. "Cada parcela do território urbano é valorizada (ou desvalorizada) em virtude de um jogo de poder exercido ou consentido pelo Estado" (SANTOS, 1994, p. 122). Assim cada contexto urbano envolve diferentes debates correlacionados ocorridos no Estado, como comentado no tópico anterior. Desta maneira, como resultado de todo processo de disputa, há de se reconhecer a existência na sociedade contemporânea de uma desigualdade social, ou seja, há uma desigualdade na forma de se apropriar do território; fato este inerente ao sistema capitalista. Contudo, tal desigualdade possibilita que os impactos ambientais não sejam sentidos por todos os moradores de um determinado município da mesma forma, e sim que uma parcela da população arque com o maior ônus no enfrentamento destes impactos, inclusive pagando com a própria vida; ao se tratar de deslizamentos de encostas ocupadas por população de baixa renda, por exemplo.

Compreender as formas de enfrentamento trazidas para o debate ambiental indica que quando a sociedade entende os ciclos naturais apenas como recurso acaba por enfrentar os limites ambientais, através da convivência com os perigos e desastres. Outro caminho de enfrentamento seria modificar o modo como a sociedade entende e lida com o meio ambiente, repensando seu modo de produção, forma de apropriação do espaço e sistema econômico. Caso contrário, resta para a sociedade monitorar tais perigos, por meio de arcabouços teóricos, medição através de mapas e indicadores, e ações paliativas e 
pontuais; como ocorre hoje com o CEMADEN - Centro Nacional de Monitoramento e Alertas de Desastres Naturais (CEMADEN, 2021). Ou seja, hoje a sociedade já convive com a eminência de ocorrer um desastre natural, ao invés de repensar seu modo de apropriação do espaço e compreender os ciclos naturais para se viver em sociedade de uma forma tal que se tornasse obsoleta a tarefa de órgãos públicos como o CEMADEN.

Após estas reflexões algumas conceituações se fazem necessárias. Os perigos são a possibilidade de ocorrência de um evento causador de prejuízo à vida humana e aos bens materiais numa área urbanizada; enquanto desastre é um evento que já se manifestou de forma concentrada no espaço, há uma comunidade específica, num determinado tempo, e que gera danos além da capacidade local e demanda assistência externa (ALMEIDA, 2011). Já os riscos podem ser considerados a probabilidade de ocorrer um processo ou conjunto de processos que ocasionem danos num determinado espaço e tempo (VARNES, 1984).

O risco também foi conceituado, por Ulrich Beck em 1986 em sua obra clássica A Sociedade do Risco, como afirma Mendes, na sua análise sobre esta obra, de que este é um "[...] estádio intermédio entre a segurança e a destruição, e a percepção dos riscos ameaçadores determina o pensamento e a ação" (MENDES, 2015, p. 212). O conceito de Beck reafirma a relação entre a construção do pensamento e a estrutura da ação, como também propõe pensar o risco como um processo e não apenas condicionado a compreensão de causas e efeitos.

Este contexto de buscas conceituais para o termo risco e o enfrentamento dos eventos ocorridos no final do século XX e início do século XXI deu origem, em 2004, a Associação Portuguesa de Riscos, Prevenção e Segurança - RISCOS, uma associação privada e sem fins lucrativos que reúne instituições e cidadãos na compreensão e divulgação da gestão dos riscos, desde a sua prevenção até à reabilitação das áreas por eles afetadas, zelando pela segurança das pessoas e dos seus bens.

O atual presidente da RISCOS e professor catedrático do Departamento de Geografia e Turismo da Faculdade de Letras da Universidade de Coimbra é Luciano Fernandes Lourenço, que também estuda categorias de risco. Para ele, há diversas categorias de riscos que podem ser analisados conforme as suas origens, há desde riscos de gênese naturais, como os riscos geofísicos (ex. vulcões), riscos meteorológicos e riscos biológicos (ex. pragas); ou riscos de gênese antrópicos, como riscos tecnológicos (ex. substâncias radioativas), riscos sociais (ex. subsistência no contexto de desigualdade social) e riscos biofísicos (desequilíbrio entre o homem e outros seres vivos, ex. epidemias); ou ainda riscos de gênese mista, como riscos mistos de componente atmosférico (ex. redução de espessura da camada de ozônio), riscos mistos de componente geodinâmico (ex. desertificação) e riscos mistos dendrocaustológico, ex. incêndios florestais em Portugal (LOURENÇO, 2007). 
Mesmo sem uma conformidade conceitual, o risco passa a ser incorporado no cotidiano e com ele as buscas por métodos de prever o incerto. Apesar da variabilidade das formulações do risco, no processo de mensurar seus componentes há uma constante, a abordagem da vulnerabilidade; compreendendo-a como a fragilidade dentro de uma conjuntura, que pode aumentar o risco e os possíveis impactos do evento previsto.

Não é de se estranhar que, da mesma forma que o risco, a vulnerabilidade não possui um consenso conceitual. Apesar de conexos, risco e vulnerabilidade possuem diferentes trajetórias, sendo o risco a busca por prever um evento visando a segurança da vida humana e dos seus bens; possui um viés para as agendas das engenharias e das geociências, com os cálculos de probabilidade estatística e mecanismos de contenção do possível impacto; enquanto a vulnerabilidade por ser "[...] intrínseca de um indivíduo ou grupos de indivíduos" (ALMEIDA, 2011, p. 88) possui um viés para as ciências sociais aplicadas, por tratar da relação do ser humano, que vive em sociedade, com o meio por ele construído e constituído. A vulnerabilidade foi incorporada pelo debate ambiental como uma busca de resgatar, ou trazer à tona, uma visão mais abrangente.

Através das décadas, estes estudos passaram por algumas mudanças de enfoque, procurando incorporar perspectivas mais holísticas e complexas, visando compreender a intricada rede de relações humano-físico-sociais que estão na base da trama genética dos desastres (HOGAN; MARANDOLA JR, 2006, p. 33).

Neste interim, Cutter (1996) defendendo uma "ciência da vulnerabilidade", lista dezoito definições do termo, que reafirmam o não consenso em torno deste, como também demonstra uma preocupação crescente em torno da vulnerabilidade dada nas últimas décadas, principalmente com a ocorrência de desastres em maior quantidade e magnitude, de tal modo que possibilitou um enriquecimento do termo debatido para uma conceituação mais complexa englobando uma diversidade de elementos, uma vez que "[...] a ideia de vulnerabilidade ganha vulto exatamente por permitir estudar a dinâmica dos desastres para além do espaço circunscrito do evento" (HOGAN; MARANDOLA JR, 2006, p. 36). Ou seja, a vulnerabilidade busca compreender os processos e relações dados em diferentes dimensões (do saber sobre a realidade) e nas escalas (seja a global, regional ou local) correspondentes que, em conjunto, resultaram num evento específico dado num determinado tempo e espaço.

\section{VULNERABILIDADE URBANA}

Neste trabalho, já se afirmou que a vulnerabilidade possui um viés para as ciências sociais aplicadas devido à sua busca de compreender os processos das relações humanas, 
tanto entre si quanto com o seu meio. Buscando o uso do termo vulnerabilidade nas últimas décadas, notou-se que este tem sido incorporado em diversas disciplinas como a saúde, a educação, a tecnologia, a economia e os cursos de gestão, entre outros; não se restringindo apenas ao campo das ciências sociais aplicadas. A partir desta pesquisa também se constatou a crescente utilização de um sufixo ou qualificação para a vulnerabilidade, como por exemplo, vulnerabilidade social, vulnerabilidade ambiental, vulnerabilidade do consumidor, vulnerabilidade financeira e vulnerabilidade tecnológica.

Tais categorizações trazem uma dualidade, uma vez que auxilia na compreensão e divulgação de pesquisas de grupos vulneráveis às doenças ou à exclusão social, por exemplo; crescendo o número de pesquisas e artigos científicos voltados para a vulnerabilidade na última década. No entanto, acaba por direcionar o entendimento da vulnerabilidade apenas como uma fragilidade dentro de uma conjuntura específica, não abarcando o olhar mais abrangente como mostra Simone Monteiro no artigo que relata uma compreensão do termo vulnerabilidade a partir da ótica da assistência social, visando a implantação de políticas públicas pelo SUAS (Sistema Único de Assistência Social), afirmando que a "[...] vulnerabilidade deve ser compreendida a partir da relação dialética entre externo e interno. O externo refere-se ao contexto de referência, já o interno pauta-se em características básicas de indivíduos, grupos, lugares ou comunidades" (MONTEIRO, 2011 , p. 34). Para demonstrar a pesquisa realizada pelos autores, têm-se a tabela 1 que retrata a quantidade de grupos de pesquisas cadastrados no CNPq, dentro da linha de pesquisa em planejamento urbano e regional, que estudam vulnerabilidade, podendo notar o número considerável de pesquisadores envolvidos com a temática.

Tabela 1 - Quantidade de grupos de pesquisa, com linhas de pesquisa relacionada ao PLUR

Temática de estudo

Fonte: CNPQ, 2021.

\begin{tabular}{l}
$\begin{array}{c}\text { Quantidade de grupos de pesquisa, com linhas de pesquisa relacionad } \\
\text { PLUR } \\
\text { Temática de estudo }\end{array}$ \\
$\begin{array}{c}\text { Quantidade de grupos de pesquisa } \\
\text { cadastrados no CNPq }\end{array}$ \\
\hline vulnerabilidade \\
vulnerabilidade social \\
vulnerabilidade ambiental \\
vulnerabilidade urbana \\
Fonte: CNPQ, 2021.
\end{tabular}

Além destes diversos pesquisadores brasileiros que buscam compreender a vulnerabilidade, há também oito grupos de pesquisa que estudam a vulnerabilidade urbana; haja visto os grupos de pesquisa de diversas áreas e com linhas específicas na área de Planejamento Urbano e Regional (PLUR). Conforme registro junto ao CNPq (Conselho Nacional de Desenvolvimento Científico e Tecnológico), com linhas de pesquisa relacionadas à área do PLUR e que analisam a vulnerabilidade urbana, foi contatado o que demonstra a figura 1. Ao observar estes grupos de pesquisa nota-se uma diversidade de 
áreas de atuação e que se articulam na formulação dos saberes, como as ciências sociais aplicadas, ciências humanas, engenharias, ciências exatas e da terra, ciências da saúde; e uma abrangência territorial da localização das instituições que estudam tal tema, tendo as instituições localizadas nas regiões sudeste, sul e nordeste do país. Assim, pode-se afirmar a crescente relevância da temática da vulnerabilidade urbana no Brasil.

Figura 1 - Grupos de Pesquisa, com linhas de pesquisa relacionada ao PLUR, que estudam a vulnerabilidade urbana

\begin{tabular}{|c|c|c|c|c|}
\hline (2) Clipo & $\begin{array}{l}\text { Consulta Parame trizada por Grupos de } \\
\text { cadastrados, com linhas de pe squisa re } \\
\text { Planejamento Urbano e Regional, que e } \\
\text { VULNERABILIDADE URBANA }\end{array}$ & $\begin{array}{l}\text { Pesquisa } \\
\text { elacionada ao } \\
\text { estucham }\end{array}$ & & \\
\hline NSTIIUICAOO & GRUPO & LIDEA & 2*LIDER & $\begin{array}{l}\text { AREA } \\
\text { PREDOM }\end{array}$ \\
\hline $\begin{array}{l}\text { Fundaçao Univer sidade Regional de } \\
\text { Blumenau }\end{array}$ & $\begin{array}{l}\text { ANÄLLISE AMBIENTALE } \\
\text { ECODESENVOLVIMENTO }\end{array}$ & $\begin{array}{l}\text { Cristiane Mansur } \\
\text { de Moraes Souza }\end{array}$ & $\begin{array}{l}\text { Gilbento } \\
\text { Friedenteich dos }\end{array}$ & $\begin{array}{l}\text { Ciéncias Sociais } \\
\text { Aplicadas }\end{array}$ \\
\hline $\begin{array}{l}\text { Universidade Estadual Paulista Júlio de } \\
\text { Mesquita Filho }\end{array}$ & Cartografia Ambiental Urbana & Reinaldo Lorandi & Reinaldo Lorand & Engenharias \\
\hline Fundaçao Oswaldo Cruz & $\begin{array}{l}\text { Deservolvimento Local, Determinantes } \\
\text { Sociais da Saude e Ambiente e }\end{array}$ & $\begin{array}{l}\text { Simone Cynamon } \\
\text { Cohen }\end{array}$ & $\begin{array}{l}\text { Débora Cynamon } \\
\text { Kligerman }\end{array}$ & $\begin{array}{l}\text { Ciéncias da } \\
\text { Saúde }\end{array}$ \\
\hline $\begin{array}{l}\text { Universidade Federal de Campina } \\
\text { Grande }\end{array}$ & $\begin{array}{l}\text { Grupo de Estudos em Gestao, Inovaçấo } \\
\text { e Tecnologia }\end{array}$ & $\begin{array}{l}\text { Cesinaldo Atalde } \\
\text { Candido }\end{array}$ & - & $\begin{array}{l}\text { Ciências Sociais } \\
\text { Aplicadas }\end{array}$ \\
\hline Universidade Federal de Săo Paulo & $\begin{array}{l}\text { Grupo de Estudos Sociais, Urbanose } \\
\text { Ambientais }\end{array}$ & $\begin{array}{l}\text { Humberto Prates } \\
\text { da Fonseca Alves }\end{array}$ & $\begin{array}{l}\text { Daniel Arias } \\
\text { Vazquez }\end{array}$ & $\begin{array}{l}\text { Ciências } \\
\text { Humanas }\end{array}$ \\
\hline Universidade Estadual do Ceará & $\begin{array}{l}\text { Núcleo de Allos Estudos em Pollticas de } \\
\text { Segurança e Cidadania ( NAEPS) }\end{array}$ & $\begin{array}{l}\text { Francisco Horacio } \\
\text { da Silva Frota }\end{array}$ & F & $\begin{array}{l}\text { Ciências } \\
\text { Humanas }\end{array}$ \\
\hline Universidade Federal do Paraná & Urbanização, ciđace e meio ambiente & $\begin{array}{l}\text { Myrian Regina Del } \\
\text { Vecchio de Lima }\end{array}$ & $\begin{array}{l}\text { Myrian Regina Del } \\
\text { Vecchio de Lima }\end{array}$ & $\begin{array}{l}\text { Ciéncias } \\
\text { Humanas }\end{array}$ \\
\hline $\begin{array}{l}\text { Instituto Federal de Educaçá, Ciência e } \\
\text { Tecnologia da Paralba - IFPB }\end{array}$ & $\begin{array}{l}\text { Vulnerabilidades Urbanas e } \\
\text { Socioambientais }\end{array}$ & $\begin{array}{l}\text { Frederico Campos } \\
\text { Pereira }\end{array}$ & $\begin{array}{l}\text { Frederico Campos } \\
\text { Pereira }\end{array}$ & $\begin{array}{l}\text { Ciências Exatas } \\
\text { e da Terra }\end{array}$ \\
\hline
\end{tabular}

Fonte: CNPQ, 2021.

Neste contexto se faz necessário conceituar o que se entende por urbano, principalmente ao se pontuar uma vulnerabilidade urbana. Para tal debate se utiliza os escritos de Roberto Monte-Mór que, ao tratar dos termos urbano e rural, destaca que estes não se referem apenas à cidade e ao campo, mas que "[...] recentemente e dizem respeito a uma gama de relações culturais, socioeconômicas e espaciais entre formas e processos derivados da cidade e do campo sem, no entanto, permitirem a clareza dicotômica que os caracterizava até o século passado" (MONTE-MÓR, 2006, p. 6). Assim percebe-se que o urbano é a representação social da estruturação do e no espaço de uma cidade, sendo definido pelas relações socioespaciais ali estabelecidas. Se, por um lado o urbano é legalmente compreendido como a população que mantêm moradia no interior dos perímetros urbanos dos municípios, sendo essa a população urbana contabilizada pelo IBGE (Instituto Brasileiro de Geografia e Estatística), por outro, se compreende o urbano 
como fruto das relações culturais, socioeconômicas, políticas e espaciais; qual seja, um modo de viver.

É relevante pontuar que o contexto urbano criado na contemporaneidade como resultante de um processo de produção industrial e de incentivo ao consumismo gera um ambiente propício aos impactos ambientais. Como afirma Jacobi (2004), as áreas urbanas se tornaram o contexto de aceleração dos riscos ambientais, com a redução de áreas verdes, poluição do ar, rede de transporte privilegiando o automóvel, falta de uma rede de esgoto, contaminação de rios e despejo de lixo que geram contaminação das águas subterrâneas e de superfície pelo chorume.

\begin{abstract}
Os problemas relativos à cidade, à urbanização e ao ambiente urbano parecem, todavia, não se restringir a uma visão dialética estreita que toma somente duas variáveis possíveis da questão ambiental, afinal o fato urbano é a expressão máxima e paradoxal da alteração e dependência humana de um substrato natural que a contém e lhe dá sustentação. Tornase muito difícil defender a natureza em seu estado natural na cidade, assim como também acreditar que um determinado contexto urbano apresentaria boas condições de vida destituído de elementos naturais na sua formação (MENDONÇA, 2004, p. 189, grifo nosso).
\end{abstract}

O fator urbano citado por Francisco Mendonça se refere ao urbano como modo de vida, qual seja, este urbano é dependente de um meio para produzir e expressar sua maneira de viver. Como, por exemplo, por meio de um aparelho celular fazer ligações, tirar e postar uma foto nas redes sociais e realizar transações bancárias; tudo isto se torna possível, pois tal aparelho foi produzido (por meio do uso dos recursos ambientais e dos saberes acumulados) e criado um sistema de conexão por meio de torres, que também foram produzidas e instaladas em diversos pontos do território. A apropriação do meio ambiente, utilizando-o como recurso, se deu pela exploração social por meio de trabalhos mal remunerados e a ocupação do território com tais estruturas, para que o indivíduo possa realizar estas atividades a seu modo. Por isto Mendonça cita o fator urbano como a expressão máxima e paradoxal do modo de vida humano frente às limitações do meio ambiente.

Este urbano que habita as cidades contemporâneas está vivendo, criando e replicando a vulnerabilidade no seu contexto, entendendo essa vulnerabilidade em toda sua abrangência complexa, como afirmam Penna e Ferreira (2014, p. 31-32):

A vulnerabilidade é, assim, produto de um encadeamento de processos do desenvolvimento da produção capitalista da cidade, da concentração e centralização da riqueza produzida, cujas políticas são incapazes de responder adequadamente à formação das periferias e a sua própria reprodução como sociedade e realidade urbana. 
Desta forma, evocando o processo histórico da questão ambiental, os conceitos de vulnerabilidade, o debate epistemológico e o espaço criado e ocupado pela sociedade contemporânea, propõe-se uma matriz do pensamento da vulnerabilidade urbana, no qual considera-se a vulnerabilidade do urbano (ou a vulnerabilidade urbana) como resultante de uma sobreposição de processos concomitantes - econômico, ambiental, social, institucional e espacial -, sendo a expressão máxima do ônus do processo de urbanização capitalista industrial. Representando essa ideia segue o mapa mental proposto na figura 2, que tem como linha mestra o processo de urbanização no Brasil e tece os aspectos econômico, ambiental, social, institucional e espacial; que se correlacionam e estão interligados

A vulnerabilidade urbana está vinculada ao modo de vida urbano contemporâneo, pois entende-se esta vulnerabilidade como uma resultante de um conjunto de processos e condições previamente estabelecido. Primeiramente é fruto do processo histórico de formação das cidades capitalistas industriais. Estas cidades são produto do momento histórico no qual o homem não apenas produz excedentes por meio do seu saber técnico, mas se utiliza destes para modificar seu modo de vida. Estas novas aglomerações humanas foram se tornando cada vez mais urbanas, ou seja, as cidades foram elencadas como o lócus do modo de vida na era moderna.

Estruturou-se este mapa mental (demonstrado na figura 2), a partir do entendimento da atual conjuntura do modelo de sociedade capitalista industrial ser de uma sociedade na qual coexistem formas de dominação e formas de emancipação. Este modelo de sociedade conduz para um modo de produção do espaço, que possui uma lógica de produzir, promover e gerir um determinado produto enquanto simultaneamente gera um resíduo ou subproduto. Por isto, três dos aspectos citados (espacial, social e ambiental) produzem intencionalmente características de uma condição e uma produção não intencional, que é o ônus do processo de urbanização. O ônus de cada um deles, quais sejam a degradação ambiental, a exclusão social e a segregação espacial em conjunto geram no território uma condição específica, que é tanto da terra quanto da pessoa que a ocupa. E essa característica, dada por um processo complexo, produz a vulnerabilidade urbana. Assim, tal analise se dá por meio de uma associação das relações sociais (com seus processos de distribuição, ou não, de renda e serviços), da existência, ou não, de infraestrutura na forma de ocupação do espaço (com o processo histórico de urbanização e modos de apropriação) e da gestão, ou não, de riscos ambientais (frutos do modo de produção econômico e dos arranjos institucionais).

Considerando esse entendimento abrangente da vulnerabilidade urbana, buscou-se autores do Sul que também estudassem tal temática. Num primeiro momento três pesquisadores se destacam, Lúcio Kowarick, Daniel Hogan e Eduardo Marandola Jr. O primeiro analisa a literatura norte americana, depois a francesa e por fim, traz um olhar para 
a realidade brasileira, com o objetivo de "[...] mostrar os conteúdos e os contornos que a questão social adquire em função das especificidades próprias de cada ambiente sociopolítico nacional" (KOWARICK, 2003, p. 62).

Figura 2 - Mapa mental

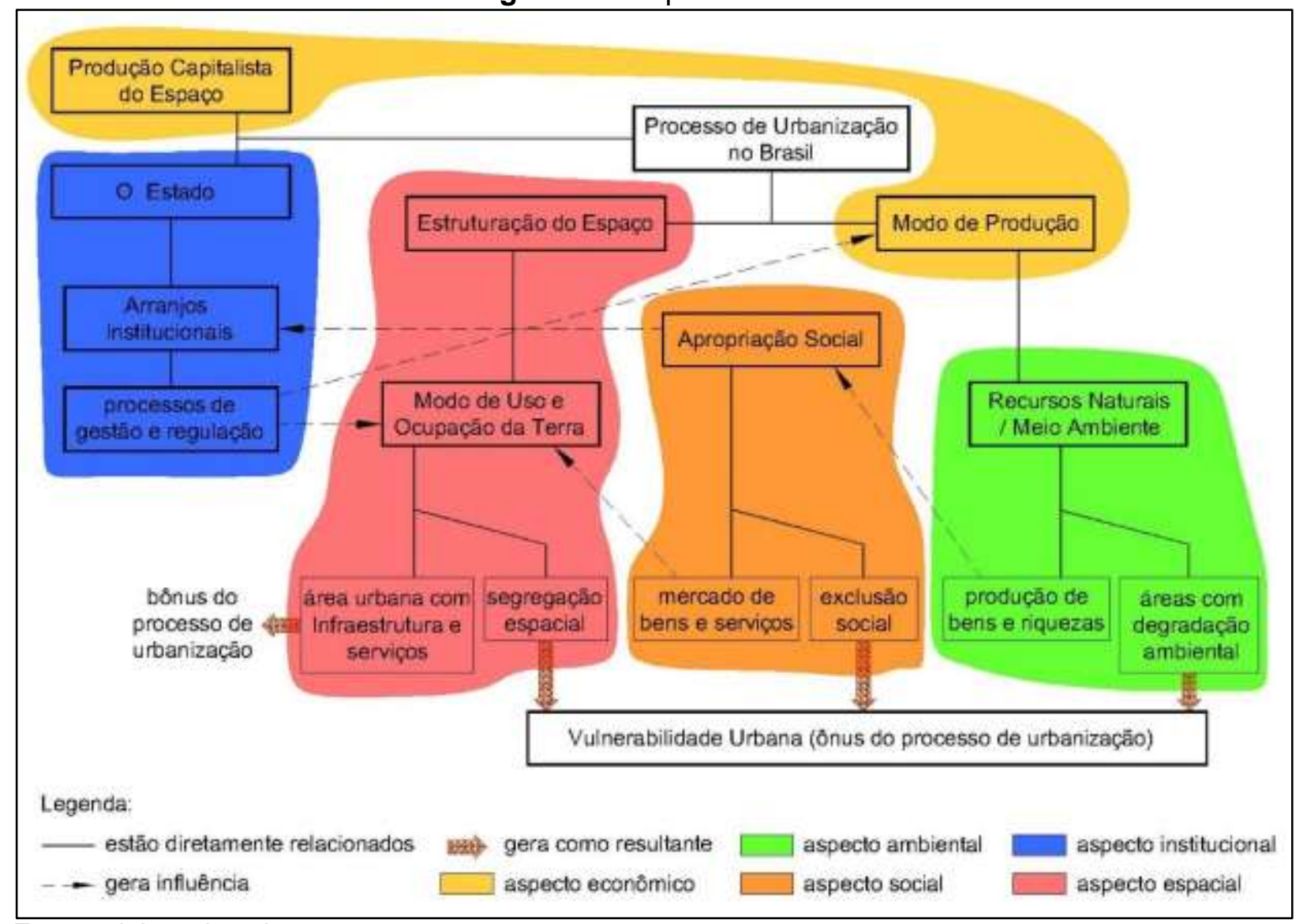

Fonte: elaborado pelos autores.

Os outros dois autores que analisam a vulnerabilidade no mesmo contexto que este artigo busca fazer são Daniel Hogan e Eduardo Marandola Jr., ao afirmarem: "[...] o reconhecimento de que a vulnerabilidade envolve uma gama de fenômenos de natureza multidimensional e multifacetada, que torna imperativo o diálogo e um olhar mais abrangente diante do tema" (MARANDOLA Jr.; HOGAN, 2006, p. 35). Estes autores abordam a vulnerabilidade frente às diferentes disciplinas ou campos de pesquisa, iniciando pelas ciências sociais, comentam sobre a abordagem AVEO ou a abordagem com enfoque nos ativos, vulnerabilidade e estrutura de oportunidade, conforme descreve Rubén Kaztman (1999); e a relevância da vulnerabilidade em mapear as condições sociais atuais, percorrendo o caminho do entendimento da exclusão social e pobreza dentro do seu contexto. "Diferente do que ocorreu em outras ciências, nas quais a vulnerabilidade entra na tradição dos estudos sobre riscos e perigos, estas preocupações, dentro das ciências sociais, não percorreram o mesmo caminho (MARANDOLA Jr.; HOGAN, 2006, p. 36). 
Este presente trabalho entende a vulnerabilidade urbana como um conceito abrangente e no contexto do debate das ciências sociais no Brasil. Assim esta pesquisa buscou compreender a abordagem AVEO, citada por Marandola Jr. e Hogan (2006) e defendida pelo pesquisador e professor emérito da Universidade Católica do Uruguai, Rubén Kaztman (1999). A abordagem com enfoque nos Ativos, Vulnerabilidade e Estrutura de Oportunidade é resultado de um estudo da Comisión Económica para América Latina y el Caribe - CEPAL - mais especificamente da Oficina de Montevidéu. Tal abordagem da vulnerabilidade visa compreender a heterogeneidade dinâmica das desigualdades sociais.

A partir de la relación Activos, Vulnerabilidad, Estructura de Oportunidades, estimula un análisis acerca del papel de las políticas sociales, pero también se cuestiona sobre la gestión emancipadora por parte de los individuos, hogares y comunidades en el proceso de la movilidad social (OJEDA, 2019, p. 150).

Portanto, permite uma análise abrangente, ou seja, uma análise micro e macro social, ponderando o contexto histórico e das relações sociais existentes. Observando a conceituação da abordagem AVEO e em paralelo o mapa mental proposto aqui, observa-se que os aspectos contemplados são congruentes, buscam compreender e contemplar o processo histórico na análise, entendendo que as mazelas sociais não possuem apenas o olhar de causa e efeito; mas sim na sobreposição de processos dados num determinado lugar. Como pode ser visto nos ativos que englobam o capital físico que está depositado nos direitos, pois se trata de recursos financeiros e bens materiais, o capital humano que está depositado na pessoa, que trata das habilidades do indivíduo; e o capital social está depositado nas relações sociais, iniciando pela família e pelo bairro. As estruturas de oportunidades são dadas pelo Estado, pelo mercado e pela sociedade (KAZTMAN, 2000).

Visto que, segundo Ojeda (2019), um dos grandes desafios da abordagem com enfoque nos Ativos, Vulnerabilidade e Estrutura de Oportunidade é a definição dos seus indicadores, propõe-se o resgate do debate da vulnerabilidade de forma abrangente, a partir dos estudos já existentes de autores do Sul, considerando a vulnerabilidade urbana como fruto de um processo histórico, dada num determinado espaço e tempo; tal como ocorre com a abordagem AVEO, que se trata de um aporte técnico, desenhado de maneira a dar visibilidades aos processos que resultam na pobreza e em todos os seus aspectos correlacionados, com a finalidade de uma intervenção estatal para a melhoria social. Visando a continuação e amplificação deste debate da vulnerabilidade urbana e sua abrangência conceitual, sugere-se que mais trabalhos sejam realizados nesta temática; como também estudos com proposta de indicadores para a abordagem com enfoque nos Ativos, Vulnerabilidade e Estrutura de Oportunidade. 


\section{CONCLUSÕES}

A questão ambiental já conseguiu trazer para a sociedade a reflexão dos limites ambientais frente ao modelo hegemônico de economia e de consumo contemporâneos. Sem questionar tais modelos, se propõe uma agenda internacional de proteção ao meio ambiente, colocando como condutor o Estado. Contudo o Estado é fruto do contexto social no qual está inserido e, atualmente, encontra-se no momento neoliberalista.

Desta forma, o Estado não apenas conduz ações para proteger o meio ambiente, mas sim atende as demandas estipuladas pelos agentes que predominam nos locais de governança; que não necessariamente visam proteger o meio ambiente, e por vezes, demandam utilizar este como recurso visando o lucro. Os espaços, receptores das relações sociais e, dentre elas, as atuações do Estado, se tornam fragmentados e desiguais.

Tais desigualdades possibilitam que os impactos ambientais não sejam sentidos por todos os moradores de um determinado território da mesma forma. Neste contexto se formula o entendimento de risco como a probabilidade de ocorrer um processo que ocasione danos, pontuando a vulnerabilidade como a fragilidade dentro de uma conjuntura, que pode aumentar o risco e os possíveis impactos do evento previsto. Este entendimento é válido para articulação de ações de monitoramento e alerta a desastres naturais, por exemplo; mas mantem a relação de constante vitimização de uma parcela da sociedade.

Assim, a partir da compreensão da relação entre a construção do pensamento e a estrutura da ação, propõe-se o uso da terminologia vulnerabilidade urbana, entendida como uma resultante da sobreposição de processos concomitantes (econômico, ambiental, social, institucional e espacial), sendo a expressão máxima do ônus do processo de urbanização capitalista industrial. E, valorizando a produção já existentes de autores do Sul, como o conceito da abordagem com enfoque nos Ativos, Vulnerabilidade e Estrutura de Oportunidade de Rubén Kaztman, entende-se que mais trabalhos nesse sentido se faz necessário, tal como a proposta de indicadores para a abordagem AVEO, que fomenta este debate da vulnerabilidade urbana como fruto de um processo histórico, dado num determinado espaço e tempo.

\section{REFERÊNCIAS}

ALMEIDA, Lutiane Queiroz. Por uma ciência dos riscos e vulnerabilidades na Geografia.

Mercator, Fortaleza, v. 10, n. 23, p. 83-99, 2011.

CNPQ - Conselho Nacional de Desenvolvimento Científico e Tecnológico. Consulta parametrizada. Disponível em:

http://dgp.cnpq.br/dgp/faces/consulta/consulta_parametrizada.jsf. Acesso em: 06 jan. 2021. 
CUTTER, Susan Lynn. Vulnerability to environmental hazards. Progress in Human Geography, London, v. 20, n. 4, p. 529-539, Dec.1996.

DIAS, Genebaldo Freire. A pegada ecológica e a sustentabilidade humana. São Paulo: GAIA, 2015.

FREITAS, Priscila Maria de. Direito à Cidade Sustentável. Curitiba: Appris, 2015.

GOTTDIENER, Mark. A produção social do espaço urbano. São Paulo: EDUSP, 1993.

HOGAN, Daniel Joseph; MARANDOLA Jr, Eduardo. Para uma conceituação interdisciplinar da vulnerabilidade. In: HOGAN, Daniel Joseph.; MARANDOLA JR., Eduardo. Novas metrópoles paulistas: população, vulnerabilidade e segregação. Campinas: NEPO/UNICAMP, 2006. p. 23-50.

HOGAN, Daniel Joseph. População e mudanças ambientais globais. In: HOGAN, Daniel Joseph; MARANDOLA Jr., Eduardo (org.). População e mudança climática: dimensões humanas das mudanças ambientais globais. Campinas: NEPO/UNICAMP, 2009. p. 11-24.

JACOBI, Pedro. Impactos socioambientais urbanos - do risco à busca de sustentabilidade. In: MENDONÇA, Francisco (org.). Impactos socioambientais urbanos. Curitiba: UFPR, 2004. p. 169-184.

KAZTMAN, Ruben (coord.). Activos y estructuras de oportunidades estudios sobre las raíces de la vulnerabilidad social en Uruguay. Montevideo: CEPAL, 1999. Disponível em: https://repositorio.cepal.org/bitstream/handle/11362/28651/LCmvdR180_es.pdf?sequence=1 \&isAllowed=y. Acesso em: 20 fev. 2021.

KAZTMAN, Rubén. Notas sobre la medición de la vulnerabilidad social. México: CEPAL, 2000.

KOWARICK, Lúcio. Sobre a vulnerabilidade socioeconômica e civil. Estados Unidos, França e Brasil. Revista Brasileira de Ciências Sociais, São Paulo, v. 18, n. 51, p. 61-85, 2003.

LEFEBVRE, Henri. A produção do espaço. Paris: Éditions Anthropos, 2006.

LOURENÇO, Luciano. Riscos naturais, antrópicos e mistos. Territorium, [S. I.], n. 14, p. 109-113, 2007.

MARANDOLA Jr., Eduardo; HOGAN, Daniel Joseph. As dimensões da vulnerabilidade. São Paulo em Perspectiva, São Paulo, v. 20, n. 1, p. 33-43, 2006.

CEMADEN - Centro Nacional de Monitoramento e Alertas de Desastres Naturais. Rede de Dados e Mapa Interativo. Disponível em:

http://www.cemaden.gov.br/categoria/redededados/ e http://www.cemaden.gov.br/mapainter ativo/\#. Acesso em: 20 fev. 2021.

MENDES, José Manuel. Ulrich Beck: a imanência do social e a sociedade do risco. Análise Social, Lisboa, n. 214, p. 211-215, mar. 2015.

MENDONÇA, Francisco. SAL - Sistema Ambiental Urbano: uma abordagem dos problemas socioambientais da cidade. In: MENDONÇA, Francisco (org.). Impactos socioambientais urbanos. Curitiba: UFPR, 2004. p. 185-207.

MONTE-MÓR, Roberto Luís de Melo. O que é o urbano, no mundo contemporâneo. Belo Horizonte: UFMG/Cedeplar, 2006.

MONTEIRO, Simone Rocha da Rocha Pires. O marco conceitual da vulnerabilidade social. Sociedade em Debate, Pelotas, v.17, n. 2, p. 29-40, jul./dez. 2011.

NOBRE, Carlos Afonso. Mudanças climáticas globais: possíveis impactos nos ecossistemas do país. Parcerias estratégicas, Brasília, v. 6, n. 12, p. 239-258, 2001. 
NUNES, João Arriscado. O resgate da epistemologia. In: SANTOS, Boaventura de Sousa; MENESES, Maria Paula (org.). Epistemologias do Sul. São Paulo: Cortez, 2013. p. 215242.

ONU - Organização das Nações Unidas. A ONU e o Meio Ambiente. Disponível em: https://brasil.un.org/pt-br/91223-onu-e-o-meio-ambiente. Acesso em: 10 dez. 2020.

PENNA, Nelba Azevedo; FERREIRA, Ignez Barbosa. Desigualdades socioespaciais e áreas de vulnerabilidades nas cidades. Mercator, Fortaleza, v. 13, n. 3, p. 25-36, set./dez, 2014.

PRADO Jr, Caio. História econômica do Brasil. São Paulo: Brasiliense, 1945.

OJEDA, Daliana Ramos. Understanding the social vulnerability: a look from its principal theorists. Estudios del Desarrollo Social, La Habana, v. 7, n. 1, p. 139-154, abr. 2019. SACHS, Ignacy. Ecodesenvolvimento: crescer sem destruir. São Paulo: Vértice, 1986.

SANTOS, Boaventura de Sousa; ARAÚJO, Sara; BAUMGARTEN, Maíra. As epistemologias do Sul num mundo fora do mapa. Sociologias, Porto Alegre, v. 18, n. 43, p. 14-23, 2016.

SANTOS, Boaventura de Sousa. Para além do pensamento abissal: das linhas globais a uma ecologia de saberes. In: SANTOS, Boaventura de Sousa; MENESES, Maria Paula (org.). Epistemologias do Sul. São Paulo: Cortez, 2013a. p. 23-71.

SANTOS, Boaventura de Sousa. Um ocidente não-ocidentalista?: a filosofia à venda, a douta ignorância e a aposta de Pascal. In: SANTOS, Boaventura de Sousa; MENESES, Maria Paula (org.). Epistemologias do Sul. São Paulo: Cortez, 2013b. p. 445-486.

SANTOS, Milton. Por uma economia política da cidade. São Paulo: Hucitec, 1994.

SANTOS, Milton. Por uma outra globalização: do pensamento único à consciência universal. Rio de Janeiro: Record, 2002.

STEINBERGER, Marília. A inseparabilidade entre Estado, políticas públicas e território. In: STEINBERGER, Marília Território, estado e políticas públicas espaciais. Brasília: Libri Editorial, 2013. p. 31-64.

VARNES, David Joseph. Landslide Hazard Zonation: review of Principles and Practice. Paris: UNESCO Press, 1984.

VEIGA, José Eli da. A insustentável utopia do desenvolvimento. In: LAVINAS, Lena et al. Reestruturação do espaço urbano e regional no Brasil. São Paulo: Hucitec, 1993. p. 149-169.

\section{AGRADECIMENTOS}

Os autores agradecem ao Conselho Nacional de Desenvolvimento Científico e Tecnológico $\mathrm{CNPq} /$ Capes, pela bolsa de doutorado concedida à primeira autora. O presente trabalho foi realizado com apoio da Coordenação de Aperfeiçoamento de Pessoal de Nível Superior Brasil (CAPES) - Código de Financiamento 001.

Recebido: agosto de 2020. Aceito: fevereiro de 2021. 